\title{
UM GOSTINHO DO PRÓPRIO REMÉDIO: até \\ que ponto empresas de consultoria no Brasil adotam em si mesmas aquilo que prescrevem a seus clientes?
}

Miguel Caldas et al.

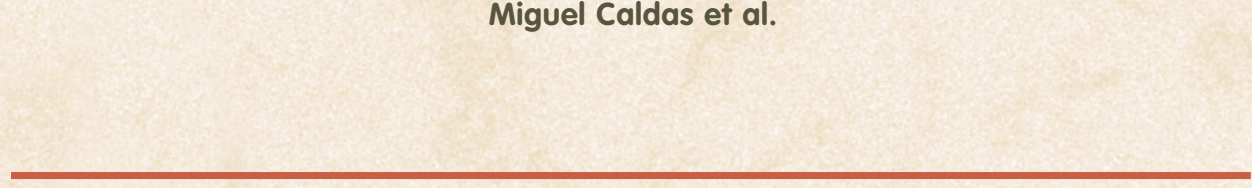

"Pimenta nos olhos dos outros é refresco." Provérbio popular

\section{INTRODUÇÃO}

O filme "Um golpe do destino" ("The Doctor", 1991) conta a história do Dr. Jack McKee, um talentoso médico cardiologista. O Dr. McKee é rico, bem-sucedido e extremamente autoconfiante: um mestre no seu campo. Entretanto, ele desenvolveu uma forma peculiar de lidar com seu trabalho, com seus pacientes e com sua profissão. Para o Dr. McKee, seu trabalho é uma grande diversão: ele se deleita tripudiando sobre a inaptidão de colegas menos experientes; ele acha engraçado cantar, dançar e brincar com os instrumentos cirúrgicos enquanto conduz uma delicada operação, que ele transforma em um alegre divertimento para toda a equipe cirúrgica, e ele parece gostar muito de entreter seus pacientes com piadas de mau gosto logo após lhes dar um chocante e doloroso diagnóstico. Em suas aulas, ele ensina a seus estudantes como se distanciar dos casos de que cuidam, de forma a reter a objetividade, e, com seu exemplo, ele os treina para que se divirtam no processo. Um belo dia, o próprio Dr. McKee adoece, vitimado por um câncer de garganta. $\mathrm{O}$ enredo se desenvolve à medi- 
da que ele descobre o que é ser um paciente e a diferença entre tratamento e cuidado médico. Não mais o Dr. Jack McKee, ele se torna um caso; ele aprende a sentir como indiferença o que seus médicos chamam de objetividade médica; ele descobre insensibilidade disfarçada sob a burocracia e o profissionalismo de hospitais e tratamentos e ele encontra medo e dor naquilo que seus médicos chamariam de condição clínica. Mas, acima de tudo, o Dr. McKee aprende muito sobre si mesmo. Além de uma história comovente, o enredo do filme é um incômodo insight, um lembrete para muitos de nós que, ao prover serviço, ajuda ou orientação para outrem, freqüentemente esquecemos como realmente são as coisas do outro lado.

Há algum tempo, durante um projeto de consultoria, usei o filme para o treinamento de um grupotarefa que estava sendo designado pela organização para assumir e conduzir um turnaround em uma fábrica que haviam incorporado durante um processo de aquisição. De início, fiquei satisfeito em ver como a mensagem tinha sido bem entendida e recebida: o respeito e a decência que o grupo-tarefa demonstrou em relação às pessoas que encontraram na fábrica adquirida têm sido citados em seu segmento como modelos exemplares de comportamento do adquirente em processos de turnaround; além disso, as pessoas, quando no cliente, freqüentemente se referem ao filme como uma referência comum. Mais tarde, porém, fui surpreendido por quão útil e reflexiva tem sido a história do Dr. McKee no meu ensino de mudança organizacional e consultoria administrativa. Talvez seja porque a metáfora médica do consultor de empresas tenha se tornado bastante intuitiva ou talvez porque uma onda crescente de crítica tem questionado recentemente a

questão da consultoria (ir)responsável. De uma forma ou de outra, é impressionante descobrir como - ao discutir a história com estudantes ou com outros consultores - podemos nos identificar tão facilmente com várias dessas expe-

\section{Ao prover serviço, ajuda ou orientação para outrem, freqüentemente esquecemos como realmente são as coisas do outro lado.}

riências, seja como consultores, seja como seus objetos. Afinal, parece que hoje em dia existem mesmo consultores demais que se assemelham com o Dr. McKee: há muitos aplicando tratamento impessoal e talvez muito poucos que se importam ou que realmente já tenham experimentado "um gostinho do próprio remédio".

\section{Consultores administrativos, "médicos organizacionais" \\ e criadores de modismos}

Desde os anos 70 e 80 , o ambiente empresarial ocidental tem testemunhado a formação e o crescimento de um tipo efêmero e modal de mudança e intervenção organizacional. Ano após ano, empresas gastam milhões de dólares na adoção da última panacéia gerencial (Gill e Whittle, 1992), freqüentemente em nome da busca frenética pelo "Santo Graal" da competitividade local e global. E, ano após ano, tais panacéias aparecem em volume crescente, sua demanda expande-se em proporções impressionantes, enquanto sua longevidade cai cada vez mais (Abrahamson, 1996; Abrahamson e Fairchild, 1997).

Culpar os consultores como os principais agentes na criação e di- fusão de tais modismos e panacéias administrativas parece ter-se tornado um clichê na literatura sobre inovações gerenciais. Na verdade, tal argumento tem sido repetido há um bom tempo, tanto na literatura acadêmica, que discute modismos administrativos (por exemplo, Hirsch, 1972; Mintzberg, 1979; DiMaggio e Powell, 1983; Abrahamson, 1991, 1996; Gill e Whittle, 1992), quanto na literatura gerencial (The cracks..., 1992; Re-engineering..., 1994; Bleakley, 1993; Jacob, 1993) a respeito. Por outro lado, nos últimos anos, e mais intensamente desde fins de 1996 , tem havido um movimento crescente de questionamento e crítica de modismos administrativos, não apenas na mídia de negócios mas também em círculos acadêmicos, naquilo que já foi chamado de modismo do antimodismo gerencial (Abrahamson e Fairchild, 1997).

Rapidamente, tal onda de crítica também tem sido estendida aos gurus de negócios e, em especial, a consultores de administração (por exemplo, Confessions..., 1996; Lieber, 1996; Farnham, 1996). O principal argumento desses críticos é que os consultores seriam os principais agentes, na sociedade, do processo de criação, difusão e comercialização de modismos administrativos, disfarçados em "pacotes" de intervenção e mudança organizacional. Tais críticos argumentam que os consultores tendem a disseminar tais pacotes, para, em seguida, abandoná-los e trocá-los por novas panacéias com a intenção de gerar uma demanda contínua e, portanto, um mercado autosustentado para si mesmos (Abrahamson, 1996; Caldas, 1996).

Segundo essa linha de crítica, os consultores modernos estão cada vez mais distantes da mítica imagem de "médicos organizacionais", cuja missão social seria ajudar organizações a diagnosticar, tratar e 
prevenir "patologias" administrativas, se usarmos a metáfora médica que se tornou muito popular na área de negócios. Isto é, para esses críticos, a transformação do ofício de consultoria em um mercado organizado estaria fazendo o "médico organizacional" tornar-se uma parte do problema, um elemento da patologia que os consultores deveriam estar ajudando a prevenir e a erradicar.

\section{Há muitos consultores aplicando tratamento impessoal e talvez muito poucos que se importam ou que realmente já tenham gostinho do próprio remédio".}

Em termos dessa metáfora médica, os consultores deveriam ajudar seus pacientes a encontrar a terapia apropriada para cada patologia específica, na dosagem adequada a cada situação. No entanto, na sua versão moderna, os consultores podem estar criando e disseminando pacotes de consultoria de vida útil deliberadamente curta e de qualidade duvidosa; eles podem estar conduzindo diagnósticos apenas para legitimar receitas pré-concedidas; eles podem estar padronizando os remédios que produzem e eles podem estar massificando tratamentos.

Uma implicação lógica desse tipo de argumento é que, uma vez que pacotes de intervenção e consultoria estariam sendo criados em série apenas para consumo modal e rápido descarte para a adoção do próximo modismo, então empresas de consultoria tenderiam a não experimentar o seu próprio remédio naquelas ocasiões em que têm de lidar com os problemas internos e com as patologias que elas próprias enfrentam como grandes organizações.

\section{O objetivo do estudo}

$\mathrm{O}$ presente estudo procura investigar o argumento acima usando dados coletados - por meio de entrevistas detalhadas - sobre a adoção e/ou o consumo recente de serviços e "pacotes" de consultoria em uma amostra de vinte empresas de consultoria com operações no Brasil. Assim, o objeto da pesquisa é a adoção de programas de intervenção e mudança, metodologias e pacotes - vendidos pelos consultores a seus clientes - pelas próprias empresas de consultoria. A pergunta da pesquisa poderia ser formulada da seguinte maneira: Até que ponto empresas de consultoria, quando lidam com seus problemas internos ou quando procuram melhorar seu desempenho, compram serviços de consultoria e/ou adotam os pacotes de mudança e as metodologias que vendem como soluções a seus clientes?

O restante do artigo é estruturado da seguinte forma: a segunda seção descreve a pesquisa empírica, incluindo seu escopo, metodologia e hipóteses; a terceira seção apresenta e discute os resultados do estudo; a quarta seção trata da necessidade de desenvolvimento de relações mais saudáveis entre consultor e cliente, que deveriam estar baseadas, entre outros elementos, na idéia de empatia (subjetificação); e, por último, a seção final discute as implicações do estudo para a compreensão da mudança organizacional e para a prática de consultoria.

\section{O ESTUDO EMPÍRICO}

Os dados utilizados neste estudo foram obtidos por meio de uma pesquisa indutiva exploratória. A coleta de dados envolveu quarenta entrevistas em profundidade em vinte empresas de consultoria com operações no Brasil, feitas em fins de 1997. Nesta seção, são apresentados o escopo, a metodologia e as premissas da pesquisa.

\section{Escopo e metodologia}

Em função da natureza indutiva e dos objetivos exploratórios da pesquisa, a amostra foi desenhada para oferecer profundidade em vez de amplitude, bem como diversidade em vez de tamanho ou significância estatística. Por esse motivo, a amostra deveria incluir: a) tanto empresas de consultoria multinacionais quanto locais; b) tanto empresas grandes quanto pequenas e médias e c) tanto empresas de consultoria que oferecem múltiplos serviços quanto aquelas especializadas em um único serviço. Para maximizar a diversidade da amostra, algumas organizações de consultoria não profissionais (por exemplo, grupos de consultorias ligados a universidades ou a instituições sem fins lucrativos) foram também incluídas.

A constituição da amostra foi por si só uma tarefa laboriosa: empresas de consultoria raramente se dispõem a expor suas práticas internas e mais raramente ainda quando tal exposição pode envolver o questionamento da moralidade de suas ações. Por conseguinte, como era de se esperar, o conjunto definitivo de empresas participantes foi fechado somente após muitas negociações e substituições de última hora. Para participar, cada empresa de consultoria tinha de concordar em conceder tempo suficiente para duas entrevistas separadas e em profundidade, com dois de seus consultores. As empresas foram convidadas a "participar de uma pesquisa que iria investigar as práticas administrativas internas e de 
mudança em empresas de consultoria"; em troca, todas as empresas tiveram garantias de que os dados seriam utilizados de forma exclusivamente agregada e anônima (embora concordassem em serem listadas entre as participantes) e de que iriam receber um resumo dos resultados. Por razões óbvias, diversas empresas (20\% da lista inicial) não quiseram aderir e tiveram de ser substituídas. Ao final do processo, a amostra foi constituída pelas seguintes organizações (em ordem alfabética): Andersen Consulting, AT Kearney, Booz Allen, Boucinhas e Campos, BSR, Consultoria Jr. Pública da FGV, Coopers \& Lybrand, Deloitte \& Touche, Directa, Dorsey e Rocha, Empresa Jr. da EAESP, Ernst Young, Fundação Cristiano Ottoni, Gemini, GVconsult, KPMG, MGDK, Price Waterhouse, Putterman e Trevisan ${ }^{1}$.

Em relação ao método de coleta de dados, a pesquisa utilizou informações obtidas por meio de entrevistas estruturadas e em profundidade com membros designados das empresas da amostra. Duas entrevistas foram feitas em cada empresa: uma deveria ser feita com um representante de alto escalão da organização e uma deveria ser realizada com membros dos níveis intermediários ou técnicos. Na amostra final, 37 entrevistas continham dados utilizáveis: em algumas ocasiões, dirigentes das empresas tentaram controlar as duas entrevistas ou insistiram em estar presentes durante a segunda entrevista (com o representante dos escalões inferiores): os dados finais excluíram as informações obtidas nesses encontros "controlados", para evitar potenciais vieses. Em duas ocasiões distintas, as informações fornecidas pelos representantes da empresa eram totalmente contraditórias: quando não era possível descartar as duas respostas - por exem- plo, quando só se podia admitir uma resposta para determinar se a empresa tinha ou não contratado consultores externos -, a resposta do representante de maior nível hierárquico foi tomada como mais bem informada, e a outra foi descartada.

\section{Culpar os consultores como os principais agentes na criação e difusão de modismos}

e panacéias

\section{administrativas parece ter-se tornado um clichê \\ na literatura sobre inovações gerenciais.}

Cada entrevista foi conduzida por meio de um roteiro pré-testado que só estava disponível ao entrevistador. O roteiro utilizava uma técnica progressiva (ou seja, a pessoa entrevistada só conseguia entender plenamente a pesquisa à medida que terminava a coleta). Primeiramente, o roteiro colhia as características essenciais da empresa de consultoria: tamanho, origem, linha de serviços, etc. Em um segundo momento, o roteiro requeria que o entrevistado listasse os pacotes de consultoria principais e secundários oferecidos aos clientes por aquela consultoria em particular. Mais tarde, essas informações seriam usadas para testar se a adoção interna - quando existente focava-se em pacotes principais ou em pacotes de menor significância. Em um terceiro momento, pedia-se à pessoa entrevistada que enumerasse quais daqueles pacotes de consultoria (que havia listado) a empresa de consultoria teria adotado internamente nos últimos anos. Para cada pacote de consultoria mencionado como adotado, pergun- tava-se ao entrevistado se a implantação teria sido feita por consultores externos contratados ou por recursos internos, se tinha sido finalizada, bem como as razões para tais escolhas e resultados. Finalmente - e neste ponto a pessoa já entendia melhor o foco da pesquisa -, pedia-se que o entrevistado listasse as vantagens e desvantagens de as empresas de consultoria "provarem de seu próprio remédio".

\section{Hipóteses}

Orientações bem reputadas para pesquisa organizacional indutiva (por exemplo, Eisenhardt, 1997) sugerem que não devem existir hipóteses prévias nesse tipo de investigação, de forma a preservar a abertura para novos insights e visões da realidade. Assim, de acordo com tais orientações, ao engajarse em pesquisa indutiva e exploratória, o investigador deve ver as hipóteses como produto do processo. Não obstante, o presente estudo de fato partiu de algumas poucas conjecturas e, apesar de seu propósito não ter sido o de formalmente testá-las, elas serão listadas a seguir.

\section{Conjecturas de partida}

\section{Em sua maioria, as empresas de consultoria não adotam os programas e pacotes que ven- dem a seus clientes e, quando o fazem, tal adoção tende a não ser completa ou integral.}

A lógica por trás dessa primeira conjectura já foi discutida: uma implicação óbvia do argumento de que os consultores são "difusores de modismos gerenciais" (por exemplo, Abrahamson, 1991, 1996) é que, uma vez que pacotes de consultoria seriam criados somente para comércio modal e rápido descarte em favor do novo modismo na próxima estação, as consultorias não veriam sentido e utilidade efetiva em adotar elas mesmas tais pa- 
cotes. Uma outra extensão lógica desse argumento é que, se muitas empresas de consultoria podem adotar tais programas internamente, visando a obter legitimidade para seus pacotes - ou para si mesmas -, então, com base em um ponto de vista institucionalista (Meyer e Rowan, 1977), poder-se-ia prever que tal adoção tenderia a: a) ser de um pacote de menor significância (em termos absolutos ou relativos, como, por exemplo, em relação ao portfólio da própria consultoria); b) ser implantada de forma parcial ou meramente cerimonial ("para inglês ver") e/ou c) ser conduzida internamente, sem agentes (tal como consultores) externos ou independentes, que poderiam validar o nível de integralidade ou de efetividade de tal implantação.

2. A incidência de alegações de adoção deve tender a variar positivamente em relação ao nível hierárquico do respondente.

Essa segunda conjectura também seria uma extensão dos argumentos daqueles críticos que denunciam o papel dos consultores na criação e difusão de modismos gerenciais. Essencialmente, se for aceita a tese (tirada da Teoria Institucional) de que empresas de consultoria aumentariam a legitimidade social de suas práticas caso advogassem (e convencessem) que praticam o que pregam (DiMaggio e Powell, 1983), então se poderia presumir que dirigentes e representantes de mais alto escalão dessas consultorias seriam mais tentados a alegar tal adoção interna do que representantes de escalões inferiores. Assim, poderse-ia esperar que, quanto mais alto o nível hierárquico do respondente na organização, maior deveria ser a sua inclinação a alegar que a adoção interna teria ocorrido.

3. Características da empresa de consultoria, tais como tamanho, origem (multinacional ou local) e orientação do serviço (multisserviço ou monosserviço), devem afetar a incidência ou o nível de integralidade de adoções internas.

Essa terceira conjectura é a menos desenvolvida e a menos preditiva de todas as aqui apresentadas. Basicamente, ela assume que diversos elementos da empresa de consultoria devem ajudar a prever a inclinação de uma dessas firmas a adotar internamente um pacote de consultoria ou a probabilidade de tal adoção ter sido mais ou menos integral. Entretanto, não são apresentadas aqui previsões sobre a relação provável de tais elementos ou sobre os seus potenciais desdobramentos - uma das principais razões para escolher um desenho indutivo para o estudo foi justamente a possibilidade de especular mais livremente sobre a existência de tais interdependências.

\section{RESULTADOS E DISCUSSÃO}

Os resultados da pesquisa de fato trouxeram interessantes informações sobre a adoção interna tanto de pacotes de consultoria quanto de consultoria independente pelas empresas da amostra, apesar de não corroborarem todas as conjecturas preliminares.

Em relação à primeira conjectura, dados sugerem que, ao menos no que tange a declarações (postulados) de adoção, a maioria das empresas de consultoria da amostra (15 de um total de 20) alegou ter adotado alguns dos pacotes de consultoria que prescrevem a seus clientes (ver Tabela 1).

Entretanto, a alta proporção de alegações de adoção não é suficiente para demonstrar que as consultorias da amostra de fato "praticam o que pregam", quer seja de forma costumeira, quer seja de forma integral. Três elementos de informação que estão disponíveis nos dados podem nos ajudar a examinar a validade de tais alegações: o número de adoções, o nível de significância de cada adoção e a utilização de consultores externos. A primeira informação significativa é o número de adoções internas que as consultorias declararam ter feito: de todas as empresas que alegam ter adotado pacotes de consultoria que prescrevem a seus clientes, a grande maioria (9 de um total de 15) pôde enumerar não mais do que uma ou duas dessas tentativas nos anos anteriores, sendo que seis delas conseguiram listar uma única tentativa. A segunda informação relevante diz respeito à significância de cada adoção: apesar de várias das consultorias da amostra terem portfólios de serviços amplos (ou seja, eram consultorias de multisserviços), muitas conseguiram enumerar apenas tentativas de adoção de pacotes de menor significância ou inexpressivos. Por exemplo, muitas das consultorias de grande e médio porte declararam (durante a primeira parte da entrevista) que, no mais das vezes, estariam prescrevendo programas de mudança abrangentes e significativos a seus clientes, como reorientação estratégica, reengenharia, mudança e redesenho organizacional, implantação de sistemas integrados (como SAP), etc. Não obstante, quando postulavam adotar internamente alguns dos pacotes que vendiam, durante a segunda parte da entrevista, em geral, os respondentes só conseguiram enumerar categorias menos expressivas de serviços, como database marketing, planejamento de sistemas, análise de custos, etc.

Por conta disso, criou-se aqui uma medida para escalonar o nível de significância das adoções alegadas, como uma função em especial (porém não exclusiva) do portfólio da própria firma de consultoria: ou seja, além de uma medida genérica de significância (que estabelece, por exemplo, que um redirecionamento estratégico é uma adoção de maior significância do 
que a compra de um planejamento de sistemas), considerou-se neste estudo que, se uma certa adoção corresponde a um dos principais pacotes no portfólio da consultoria, seu nível de significância seria mais "alto" do que se estivesse entre os pacotes secundários oferecidos a seus clientes. Se, por sua vez, uma adoção não estivesse entre os pacotes mais prescritos e se fosse de escopo mais estreito do que as demais, seu nível de significância seria atribuído como mais "baixo" e assim por diante. Usando esse critério, cada adoção foi classificada duas vezes, por diferentes avaliadores (independentes e alheios à pesquisa), em níveis de significância "alto", "médio" e "baixo".

Por fim, uma terceira informação crítica diz respeito à utilização de consultores externos. De todas as consultorias que alegaram adotar pacotes de consultoria que comumente vendem a seus clientes, somente três usaram (se não única, ao menos significativamente) consulto- res externos independentes. De todas as tentativas de adoção reportadas (cada consultoria poderia ter várias), $80 \%$ foram conduzidas sem a contratação de serviços externos de consultoria, $13 \%$ contrataram consultores independentes e, por fim, $7 \%$ usaram outros tipos de soluções.

Ao combinar esses três elementos de informação, pode-se inferir o que se chamou neste estudo de nível de integralidade da adoção. A principal premissa é que, à medida que aumenta o produto dos três fatores

Tabela 1 - Respostas de adoção/rejeição e níveis de integralidade de adoção entre empresas da amostra (em ordem de nível de integralidade de adoção)

\begin{tabular}{|c|c|c|c|c|c|c|c|c|}
\hline Empresa & Origem & $\begin{array}{l}\text { Categoria } \\
\text { por } \\
\text { tamanho }\end{array}$ & $\begin{array}{c}\text { Orientação } \\
\text { de } \\
\text { serviço }\end{array}$ & $\begin{array}{c}\text { Alega ter } \\
\text { experiência } \\
\text { em adotar } \\
\text { os pacotes } \\
\text { que } \\
\text { vendem? }\end{array}$ & $\begin{array}{l}\text { Número } \\
\text { alegado } \\
\text { de } \\
\text { adoções }\end{array}$ & $\begin{array}{c}\text { Média de } \\
\text { significância } \\
\text { dos pacotes } \\
\text { adotados em } \\
\text { relação ao } \\
\text { portfólio da } \\
\text { própria } \\
\text { empresa }\end{array}$ & $\begin{array}{l}\text { Ao menos } \\
\text { metade das } \\
\text { adoções } \\
\text { foram implan- } \\
\text { tadas por } \\
\text { consultores } \\
\text { externos? }\end{array}$ & $\begin{array}{c}\text { Nível de } \\
\text { integralidade } \\
\text { de adoção } \\
\text { (índice) }\end{array}$ \\
\hline $\mathbf{Q}$ & Multinacional & Grande & Multisserviço & Sim & 5 & Alta & Sim & Alto (10) \\
\hline 0 & Local & Grande & Multisserviço & Sim & 4 & Alta & Sim & Alto (9) \\
\hline L & Local & Média & Multisserviço & Sim & 2 & Baixa & Sim & Médio (7) \\
\hline B & Local & Média & Multisserviço & Sim & 4 & Alta & Não & Médio (6) \\
\hline K & Multinacional & Grande & Diversos & Sim & 4 & Alta & Não & Médio (6) \\
\hline $\begin{array}{lll}T & \end{array}$ & Multinacional & Média & Multisserviço & Sim & 4 & Alta & Não & Médio (6) \\
\hline C & Multinacional & Grande & Multisserviço & Sim & 2 & Média & Não & Baixo (4) \\
\hline D & Local & Pequena & Diversos & Sim & 4 & Baixa & Não & Baixo (4) \\
\hline A & Multinacional & Média & Diversos & Sim & 1 & Média & Não & Baixo (3) \\
\hline $\mathbf{F}$ & Local & Grande & Monosserviço & Sim & 1 & Média & Não & Baixo (3) \\
\hline I & Multinacional & Grande & Multisserviço & Sim & 1 & Média & Não & Baixo (3) \\
\hline $\mathbf{R}$ & Local & Média & Diversos & Sim & 2 & Baixa & Não & Baixo (3) \\
\hline G & Multinacional & Média & Multisserviço & Sim & 1 & Baixa & Não & Baixo (3) \\
\hline H & Local & Pequena & Monosserviço & Sim & 1 & Baixa & Não & Baixo (3) \\
\hline $\mathbf{N}$ & Local & Pequena & Diversos & Sim & 1 & Baixa & Não & Baixo (3) \\
\hline E & Local & Pequena & Monosserviço & Não & --- & --- & --- & --- (0) \\
\hline$J$ & Local & Grande & Multisserviço & Não & --- & --- & --- & $---(0)$ \\
\hline M & Multinacional & Grande & Diversos & Não & --- & --- & --- & --- (0) \\
\hline $\mathbf{P}$ & Multinacional & Grande & Multisserviço & Não & --- & --- & --- & --- (0) \\
\hline $\mathbf{S}$ & Local & Grande & Multisserviço & Não & --- & --- & --- & --- (0) \\
\hline
\end{tabular}


(ou seja, quanto mais experiências de adoção interna a consultoria apresentar, quanto maior for o nível de significância das adoções e quanto maior o uso de consultores independentes), deve aumentar também a probabilidade de a adoção interna ser mais integral, ou seja, maior a chance de a consultoria de fato adotar adequadamente as adoções que prescreve, tão freqüientemente e tão efetivamente quanto for possível. Dessa forma, obteve-se aqui o nível médio de integralidade de adoção para cada consultoria (novamente por meio de dois avaliadores independentes), que podia ser "alto", "médio" ou "baixo" (maior índice possível: 10; menor índice possível: 0), como mostra a Tabela 1.

Quando sobrepostos, os dados da Tabela 1 parcialmente corroboraram a primeira conjectura. Apesar de a proporção de empresas de consultoria que postulam adoção interna ter sido maior do que o esperado, a alta proporção de adoções incompletas ou cerimoniais - ilustradas pela forte propensão de as adoções postuladas terem baixo nível de integralidade - reforça a hipótese de que a maioria das empresas de consultoria investigadas não "prova do próprio remédio", ao menos não realmente.

Por outro lado, os dados não corroboraram a segunda conjectura. Apesar de a proporção de declarações de adoção interna ter sido maior entre respondentes de alto escalão do que entre aqueles de menor nível hierárquico $(26 \%$ e $14 \%$, respectivamente), a ampla maioria $(60 \%)$ das declarações de respondentes de maior e menor escalão foi coincidente.

Por fim, o estudo encontrou pouco fundamento para a terceira conjectura. Características intrínsecas das empresas de consultoria da amostra tiveram pouca ou quase nenhuma interferência com a tendência para postular ou não a adoção interna, com a possível exceção do fator tamanho da consultoria. Embora a significância de tal relação possa ser questionável e talvez mereça testes mais específicos no futuro, os resultados da pesquisa sugerem uma correlação inversa e moderada entre o tamanho da consultoria e a tendência a postular a adoção interna, ou seja, consultorias maiores apresentaram uma moderada tendência a não postular a adoção interna, quando comparadas

\section{Os consultores podem estar criando e disseminando pacotes de consultoria de vida útil deliberadamente curta e de qualidade duvidosa.}

com consultorias de médio ou pequeno porte. Quanto à origem da consultoria, isto é, quanto à consultoria ser uma empresa multinacional ou local, os resultados da pesquisa não sugerem qualquer interdependência significativa com a tendência a postular ou não a adoção interna. O mesmo se aplica ao fator orientação de serviço: o fato de a empresa de consultoria oferecer ou não uma ampla gama de serviços não interferia na sua inclinação a postular ou não a adoção interna de programas de consultoria.

Em relação a potenciais interdependências entre as características da empresa de consultoria e o nível de integralidade das adoções internas, mais uma vez os resultados obtidos ofereceram apenas algumas poucas possibilidades para pesquisa futura. Os dados indicam uma possível correlação positiva entre tamanho da consultoria e o nível de integralidade da adoção: de todas as empresas de consultoria que postulam adoção interna, grandes organizações de consultoria apresentaram uma probabilidade moderadamente maior de suas adoções serem mais integrais. Uma relação similar envolveu orientação de serviço: entre as consultorias que alegam adoção interna, quanto mais abrangente a gama de serviços oferecidos, maior era a probabilidade de adoções mais integrais. Não apareceu nos resultados nenhuma interdependência entre a origem da empresa e o nível de integralidade de adoção.

\section{EM BUSCA DE UMA RELAÇÃO CONSULTOR- CLIENTE MAIS SAUDÁVEL}

Ao observar um contexto como o retratado pela pesquisa, parece difícil deixar de concordar que realmente podem existir consultores demais lá fora agindo como "Doutores McKees". Mas, por outro lado, conclusões genéricas são de difícil formulação. Uma vez que a atividade de consultoria cresceu vertiginosamente nos últimos anos, a ponto de tornar-se uma complexa indústria de serviços profissionais, o campo tornou-se um habitat multifacetado, um continente para uma fauna muito diversificada. É por esse motivo que definir, entender ou adjetivar a categoria "consultor" não é tarefa fácil: dizer que os consultores são charlatães, sanguessugas ou a solução de todos os males pode ser ao mesmo tempo verdade e injustiça, dependendo de que tipo de consultor e de que tipo de relação de consultoria se está retratando. É nesse sentido que, no que se refere ao fenômeno de consultores de sangue-frio que não conseguem distinguir entre tratamento e cuidado "médico", o que realmente deveria ser procurado é o desenvolvimento de relações consultor-cliente mais saudáveis. 
Em geral, um sinal da existência de uma relação não saudável entre consultor e cliente pode ser quando o consultor objetifica o cliente, isto é, quando o consultor entende o cliente como uma realidade externa, independente. E, apesar de a objetificação não ser o único fator que leva a uma relação não saudável entre consultor e cliente, esta pesquisa é um lembrete perturbador de que se trata de uma circunstância por demais freqüiente.

Em termos mais simples, dizer que o consultor objetifica um cliente significa afirmar que o consultor somente consegue ver o cliente como uma "coisa", uma entidade com a qual ele não consegue se identificar. Nesse tipo de relação, o consultor não possui uma organização-cliente: ele está tratando de um "caso"; nessa situação, o consultor está mais interessado nos problemas do que nas suas soluções: quanto mais desafiador o caso em questão, mais motivado o consultor deverá estar (Confessions..., 1996), a despeito de todo o sofrimento (por parte do cliente) que "casos desafiantes" podem implicar.

Em nossa analogia médica, o processo de objetificação remetenos ao modelo do Dr. McKee, um médico insensível para quem pacientes com nomes, sonhos e esperanças são designados apenas como "o fígado do quarto 41 " ou "o transplante do 53". No mundo dos negócios, seu correspondente é aquele tipo de consultor que interpreta sua experiência em termos do conjunto de "implementações", "certificações", "redesenhos", etc. que conduziu.

Para desenvolver relações mais saudáveis entre consultores e clientes, parece essencial, entre outros esforços, que haja um deslocamento significativo da objetificação para a subjetificação.

Essa dicotomia entre objetifica-

ção e subjetificação é similar, apesar de não idêntica, à dicotomia proposta por Edgar Schein entre consultoria médico-paciente e consultoria de procedimentos. De acordo com Schein (1977), enquanto o primeiro tipo de consultoria tende a falhar porque o "médico" (con-

\section{A alta proporção de adoções incompletas ou cerimoniais reforça a hipótese de que a maioria das empresas de consultoria investigadas não "prova do próprio remédio", ao menos não realmente.}

sultor) tende a fazer um diagnóstico e uma prescrição sem antes estabelecer uma referência comum com o "paciente" (cliente), o segundo tipo é superior justamente porque o consultor atua no sentido de apoiar o cliente a tomar suas próprias decisões e a agir por sua própria conta.

Ao construir relações de consultoria mais baseadas em subjetificação, consultor e cliente deveriam ser capazes de identificar-se inequivocamente um com o outro, e sua relação deveria ser baseada em empatia e respeito mútuos. Com esse propósito em mente, o consultor tem de estar apto a consciente e eticamente se deixar envolver com o cliente, sem perder sua objetividade; para tanto, o consultor precisa ser objetivo sem objetificar o cliente. Para muitos consultores, essa é uma tarefa muito difícil; tendese a evitar o envolvimento, seja como um mecanismo de defesa, seja porque simplesmente não se é capaz disso por inexperiência - muitos de nós nunca passamos pelas experiências que prescrevemos a nossos clientes.

\section{OUTRAS RELAÇÕES DE AJUDA: EM BUSCA DE INSIGHTS}

Não só relações de consultoria mas a maior parte das relações ditas "de ajuda" podem manifestar distorções como as aqui descritas. $\mathrm{Na}$ verdade, o trabalho de pesquisadores que estudam como melhorar tais relacionamentos, como, por exemplo, nos campos da medicina, da odontologia e da psicologia, pode nos ajudar a gerar insights para uma melhor compreensão da relação consultor-cliente.

\section{Relacionamento entre médico e paciente}

O que hoje chamamos de medicina científica surge, a partir do século XIX, tendo como base metodológica as ciências naturais da física e da química, adaptando os métodos científicos naturais ao estudo e ao cuidado do corpo humano e sua patologia. A medicina determina, em tese, de forma sistêmica, que, para toda síndrome clínica, existe uma lesão corporal anatômica correspondente. Apesar do desenvolvimento surpreendente da medicina ao longo dos anos, as limitações concernentes a esse "enfoque sistêmico" foram ficando cada vez mais evidentes. Por exemplo, o maior conhecimento dos mecanismos científicos permitiu diferenciar claramente doenças com conseqüências lesionais ao corpo humano dos distúrbios funcionais. Com isso, foi possível perceber que cerca de $50 \%$ a $75 \%$ dos doentes que procuram um clínico-geral não são portadores de doenças orgânicas, mas sim de distúrbios funcionais, para os quais as técnicas utilizadas pela medicina científica são insuficientes - já que distúrbios 
funcionais lidam com o comportamento humano e seu mundo interior (Perestrello, 1982).

O desenvolvimento das ciências comportamentais também levou à percepção de que cada indivíduo responde diferentemente às mesmas infecções. Isso ocorre porque as enfermidades funcionais estão relacionadas ao estado psíquico distinto de cada doente. Utilizando somente as ciências naturais, o médico tende a ver o paciente como uma "coisa", ou seja, ele se concentra apenas nas partes, e não no todo. A individualidade do paciente pode se perder entre diversos exames e pode haver ainda uma tendência a tratar o órgão enfermo em vez da pessoa enferma. Por isso, a medicina atualmente aceita melhor a idéia de que a relação médico-paciente necessita de uma decodificação: o médico deve saber ouvir as queixas do paciente, bem como associar as suas dores e lesões corporais ao seu estado psíquico. Para que isso ocorra, é preciso que: a) se estabeleça uma relação de confiança; b) o médico ouça e leve em conta os problemas e o estado psíquico-emocional do paciente e c) o médico considere o paciente como um indivíduo único e particular (Geammet, Reynaud e Consoli, 1982; Ealinp, 1975).

Relacionamento entre cirurgiãodentista e paciente

Esse conceito mais global da relação com pacientes também tem sido influente na formação mais recente de cirurgiões-dentistas. Autores que pesquisam a melhoria dessa relação sugerem que o conceito de dentista tem de ser transportado daquele "tecnicamente centrado no dente" para o cirurgião-dentista "biologicamente orientado e centrado no paciente". Para que isso ocorra, faz-se necessário uma mudança na atitude global do cirurgião-dentista na concepção do paciente. A própria formação tradicional do cirurgião- dentista já o induz a considerar o paciente quase que exclusivamente do ponto de vista biológico, como alguém que possui um problema dentário e que passivamente receberá os serviços considerados necessários. Contudo, o paciente não é um receptáculo passivo sobre tudo o que se decide sobre seu estado, tendo a capacidade de rejeitar ou aceitar o que lhe é oferecido. Portanto, deve-

\section{Dizer que os consultores são charlatães,} sanguessugas ou a solução de todos os males pode ser ao mesmo tempo verdade e injustiça, dependendo de que tipo de consultor e de que tipo de relação de

\section{consultoria se está retratando.}

se considerar o fato de que o paciente já chega ao consultório com seu quadro de valores, com suas atitudes, e reagirá a tudo o que lhe for oferecido de acordo com sua estrutura pessoal global, e não apenas como alguém que sente dor e quer se ver livre dela.

\section{Relacionamento entre terapeuta e paciente}

Provavelmente, o campo em que o relacionamento entre fornecedor de ajuda e paciente é estudado de forma mais aprofundada é o da psicanálise. O terapeuta pode ou não ser um graduado em psicologia. No caso de psicólogos, durante sua formação superior em psicologia e até mesmo depois dela, não há nada que os obrigue formalmente a "provar de seu próprio remédio", ou seja, passar por sessões de psicoterapia com outros terapeutas. A ausência de instrumentos formais acaba, no entanto, sendo socialmente suprida pela cobrança mútua, desaprovação e rejeição de atitudes dessa natureza por parte da sociedade de psicólogos e também por alguns pacientes. Se, por um lado, há então um efetivo "policiamento social" entre os próprios psicólogos, por outro, a persistência desse comportamento reafirma sua utilidade prática: o interesse do paciente. Por outro lado, pessoas com outras formações (ou seja, não-psicólogos) podem ser psicoterapeutas; no entanto, o indivíduo precisa ter um curso superior e, além de estudar a teoria psicanalítica e praticar análises em pacientes com a orientação de um supervisor, deve-se submeter a sessões de análise: a chamada análise didática (LaPanche e Pontalis, 1976).

Para nós, interessados na relação consultor-cliente, a relação terapeuta-paciente é uma rica analogia, pois é preciso ter em conta que, nesta última, parte do diagnóstico e da terapia evolui a partir e com base justamente na relação entre os dois. Nesse sentido, Spoerri (1972) definiu, com grande propriedade, a inter-relação psicossocial entre terapeuta e paciente como aquela "assinalada por um código socialmente determinado e por uma relação afetivo-pessoal. Essa relação terapeuta-paciente constitui fundamento para o diagnóstico e para qualquer terapêutica". Vejamos melhor essa relação.

Por parte do paciente, sabe-se que ele escolhe seu terapeuta, solicita-lhe os serviços e paga-lhe os honorários. Deposita nele sua confiança e espera, acima de tudo, postura ética, precisão diagnóstica e dedicação da parte do terapeuta. Ele traz idéias - em geral difusas - sobre a causa de seus distúrbios, bem como o desejo de ouvir um diagnós- 
tico e, sobretudo, a intenção de informar-se sobre a possibilidade de cura. A situação do paciente obriga-o a submeter-se às determinações do terapeuta e a ter vontade de sarar. Por parte do terapeuta, para atender a essas expectativas e às prescrições de seu ofício, cumprelhe encontrar a medida exata entre proximidade e distância, garantia de proteção e retraimento no tocante às pretensões regressivas do paciente. É essencial que se desenvolva um relacionamento confiante, que também pode vir a sofrer frustrações. Um estilo pessoal no trato condiciona a autenticidade do relacionamento, mas só se também em pequenas coisas for meditado e orientado com relação ao efeito a produzir. Mas sabe-se que é do ponto de vista das interações entre terapeuta e paciente que se obtém a perspectiva mais rica do processo. A observação, o interrogatório e o diálogo (fases do processo de análise) possibilitam a comunicação recíproca e, em especial, o relacionamento afetivo. No tratamento de personalidades neuróticas, isto é, levadas à doença por força de seus conflitos, o que importa, mais do que tudo, é que o médico conheça seus próprios conflitos e não ameace a terapêutica do paciente com reações complexuais. Não se quer que o médico tranque (ou "recalque") as suas próprias emoções, mas que seja afetivamente neutro à medida que a sua dedicação emocional ao doente possa orientar-se e variar. Por isso, entende-se que somente pelo conhecimento do próprio inconsciente é que se pode compreender a prática da análise, pois somente ao reconhecer em si as próprias emoções é que $o$ analista pode dominá-las. Para tanto, o analista deve ser capaz de comunicar-se mais livremente com o seu próprio inconsciente, e é precisamente isso que a análise didática deve permitir. Ou seja, o processo terapêutico supõe essencialmente que o terapeuta precisa conhecer a si próprio e às suas próprias emoções de forma a esperar ajudar seu paciente. Portanto, o intuito da análise didática é aprimorar o processo de autoconhecimento da pessoa que quer tornar-se um analista, buscando não só dar vazão a seus sentimentos, mas também dando ao candidato subsídios que o possibilitem satisfazer as necessidades individuais dos pacientes, percebidas por meio do conhecimento prático da análise, de suas nuanças e trâmites (LaPanche e Pontalis, 1976).

Nesse sentido, quer se admire ou não o processo psicoterapêutico, há de se reconhecer a valorização da crença de que o terapeuta que se submete ele próprio à terapia possui uma competência fundamental: sentir empiricamente o que significa um processo terapêutico estando no papel do paciente.

\section{IMPLICAÇÕES E CONCLUSÃO}

As implicações desta pesquisa para o estudo da mudança organizacional e da prática de consultoria administrativa parecem ser relevantes. Verificar a validade da extensão da crítica às organizações de consultoria - segundo a qual consultorias teriam um papel de liderança na criação e difusão de modismos gerenciais - tem grande importância para o entendimento da moderna atividade de consultoria administrativa. Além disso, tal investigação é importante para a compreensão das grandes mudanças que a maioria das organizações tem vivido nos últimos anos, bem como para o entendimento do papel que os consultores e modismos administrativos podem ter tido nessas mudanças. E, por fim, ao estudar detida e empiricamente os limites da influência dos consultores - na verdade, de agentes externos - na ação organizacional mais global, podemos estar colaborando para entender e agir melhor sobre a maneira pela qual as organizações se transformam e são transformadas.

\section{Consultor e cliente \\ deveriam ser capazes de identificar-se inequivocamente um com o outro, e sua relação deveria ser baseada em empatia e respeito mútuos.}

Por esses motivos, a linha de pesquisa mais ampla na qual este estudo está inserido pode produzir diversos frutos. Ela pode ajudar-nos a discernir se de fato foram apenas ou principalmente - agentes externos que causaram as sucessivas convulsões que intervenções e mudanças organizacionais têm provocado em muitas organizações em todo o mundo nos últimos anos. A partir daí, poderíamos identificar ou indicar os limites dos fatores que condicionam a ação organizacional, sejam eles externos ou internos. E, por fim, poderíamos ajudar organizações a lidar de forma mais realista e responsável com a mudança.

Como um todo - a exemplo de qualquer outro estudo indutivo -, a pesquisa levantou mais perguntas do que respostas e, portanto, abriu diversas possibilidades para futuras pesquisas. Ela deixou claro que, ao menos para a amostra examinada, consultorias podem tender a não adotar integralmente em si mesmas aquilo que prescrevem a seus clientes; entretanto, ela também deixou muitas indagações sobre por que consultorias parecem tender a postular que praticam tal adoção interna mesmo quando não o fazem e sobre por que tendem a não usar elas próprias serviços externos de consultoria. O estudo indicou que 
características internas (como tamanho, origem, amplitude de serviços, etc.) da empresa de consultoria provavelmente não são indicadores primários da tendência à adoção interna ${ }^{2}$; conseqüentemente, a questão de por que algumas consultorias adotam o que prescrevem e outras não permanece à espera de pesquisa e desenvolvimento futuro. Nesse particular, este estudo apenas se aventura a sugerir que isso pode estar mais ligado ao estilo e à cultura específicos da organização de consultoria - tal como deve estar mais ligado à visão de mundo do médico se ele de fato é diferente daquele cirurgião duro e insensível retratado no filme.

Mas, em última análise, o que nem a pesquisa nem a história do Dr. McKee respondem é: E daí? Será que tudo isso importa? Ou seja: Será que experimentar do próprio remédio faz de alguém um melhor consultor? Será que realmente entender como se sente do outro lado (ao se implementar o que se prescreve) pode produzir uma melhor prática de consultoria? Será que todos os consultores, tal como fez o Dr. McKee, precisam provar o gosto de seu próprio remédio de vez em quando? Certamente, não há garantias: podese passar pela experiência e, depois, pode-se esquecer a respeito ou podese não aprender muita coisa e, inversamente, é verdade que as pessoas de fato não precisam queimar as mãos de propósito só para entender que é doloroso. Da mesma forma, para muitos consultores lá fora, pode não ser necessário experimentar a provação que seus clientes precisam viver para que consigam se importar e efetivamente compreender aquilo pelo que os outros têm de passar. No entanto, para muitos de nós, não faria mal algum.

Miguel P. Caldas (Coord.) é Mestre e Doutor em Administração de Empresas pela EAESP/FGV, Professor do Departamento de Administração Geral e Recursos Humanos da EAESP/FGV e Consultor de Empresas. E-mail: mcaldas@fgvsp.br

Rodrigo Anunciatto, Rodrigo Arena, Felippe Barreto, Marta Bianchi, Alessandra Faccin, Marina Leite, Silvia Machado, Cássia Matsuno, Dante Pozzi, Miguel Procopiak Neto, Rodrigo Rasera, Caio Sérgio Sarhan, Leonardo Vasques e Lea Yassuda são Graduandos em Administração de Empresas na

EAESP/FGV.

\section{REFERÊNCIAS BIBLIOGRÁFICAS}

ABRAHAMSON, E. Managerial fads and fashions: the diffusion and rejection of innovations. Academy of Management Review, v. 16, n. 3, p.586-612, 1991.

ABRAHAMSON, E. Management fashion. Academy of Management Review, v. 21, n. 1, p.254-85, 1996

ABRAHAMSON, E., FAIRCHILD, G. Management fashion: lifecycles, triggers, and collective learning processes. In: ANNUAL MEETINGS OF THE ACADEMY OF MANAGEMENT, 1997, Boston, MA

BLEAKLEY, F. The best laid plans: many companies try management fads, only to see them flop. The Wall Street J ournal, July 6, 1993. A1+

CALDAS, M. Towards a more comprehensive model of managerial innovation diffusion: why consultants are not the only ones to blame. In: ANNUAL MEETINGS OF THE ACADEMY OF MANAGEMENT, 1997, Cincinnati, OH.

CALDAS, M. et al. Um gostinho do próprio remédio: até que ponto empresas de consultoria no Brasil adotam em si mesmas aquilo que prescrevem a seus clientes? São Paulo, 1997. (Working paper apresentado à EAESP/FGV).

CONFESSIONS of an ex-consultant. Fortune, v. 134, n. 7, p.69-72, 0ct. 14, 1996.
DiMAGGIO, P., POWELL, W. The iron cage revisited: institutional isomorphism and collective rationality in organizational fields. American Sociological Review, v. 48, n. 1, p.147-60, 1983.

EALINP, M. 0 médico, seu paciente e a doença. Rio de / anejro: Ateneu, 1975

EISENHARDT, K. Management theory: the case for induction. In: ANNUAL MEETINGS OF THE ACADEMY OF MANAGEMENT (Symposium Management Theory: Induction or Deduction, for the ManagementP rofession or for Ourselves?), 1997, Boston, MA

FARNHAM, A. In search of suckers. Fortune, v. 134, n. 7, p.7984,0 ct. 14, 1996.

GEAMMET, P., REYNAUD, M., CONSOLI, S. Manual de psicologia médica. Rio de J aneiro: Masson, 1982.

GILL, J., WHITTLE, S. Management by panacea: accounting fortransience. J ournal of ManagementStudies, v. 30, n. 2, p.28195, 1992

HIRSCH, P. M. Processing fads and fashions: an organizational set analysis of cultural industry systems. American J ournal of Sociology, v. 77, p.639-59, 1972.

J ACOB, R. TQM: more than a dying fad? Fortune, v. 128 n. 9, p.52-4, Oct. 18, 1993.
LAPANCHE, I ., PONTALIS, J. B. Vocabulário da Psicanálise. Lisboa: Moraes Editores, 1976.

LIEBER, R. Controlling your consultants. Fortune, v. 134, n. 7, p.74-5, Oct. 14, 1996

MEYER, J. W., ROWAN, B. Institutional organizations: formal structure as myth and ceremony. American J ournal of Sociology, v. 83, p.340-63, 1977.

MINTZBERG, H. The structuring of organizations: a synthesis of the research. Englewood Cliffs, N]: Prentice-Hall, 1979.

PERESTRELLO, D. A medicina da pessoa. 3. ed. Rio de Janeiro: Ateneu, 1982

RE-ENGINEERING reviewed. The Economist, v. 332, n 7870, p.66, J uly 2, 1994.

SCHEIN, E. Consultoria de procedimentos: seu papel no desenvolvimento organizacional. São Paulo: Edgard Blucher, 1977.

SPOERRI, T. Compêndio de Psiquiatria. Rio de Janeiro: Livraria Atheneu, 1972.

THE cracks in quality. The Economist, v. 323, n. 7755, p.678, Apr.18, 1992

THE DOCTOR. Randa Haines. Buena Vista Pictures Touchstone Home Video, 1991.123 min. (Motion picture based on a true story, based on the book A taste of my own medicine.)
Este trabalho originou-se de pesquisa financiada pelo NPP Núcleo de Pesquisas e Publicações da EAESP/FGV intitulada "A adoção interna de programas de mudança por consultorias no Brasil: até que ponto se pratica o que se prega?".

Uma versão preliminar deste artigo (mais extensa, porém sem a parte conceitual de outras relações de ajuda, feita por alunos participantes da pesquisa) será publicada no livro Transformação e realidade organizacional: uma perspectiva brasileira, de Miguel Caldas e Thomaz Wood. São Paulo: Atlas, 1999 (no prelo).

1. Uma vez que a pesquisa de campo foi realizada em fins de 1997, a amostra incluiu algumas empresas que, na data da publicacão deste artigo, tinham passado por alteraç̃es societárias, incluindo duas delas, que acabaram passando por um processo mundial de fusão.

2. Algumas possíveis interdependências relacionadas a tamanho e amplitude do serviço ainda demandam pesquisa futura, como sugerido 